\title{
Integration/Inclusion in and with Sport for All-Families, Politics, Management and Citizens in Responsibility
}

\author{
Peter Kapustin ${ }^{1,2}$ \\ 1. Institute of Sport Science, State University Würzburg, Bayern D-0931, Germany \\ 2. Sport- and Event-Management, Private University Castle Seeburg, A-5201, Austria
}

\begin{abstract}
The slogan "Sport for All" as a program of TAFISA (The Association For International Sport for All) is an invitation for all target groups and target persons in all societies worldwide to be active in sports, to organize and to create sport activities with a variety of aims. Integration and inclusion are strategies to open the world of sports for people with disabilities or a migrant background as well. Families, politics, the management within companies and all citizens are in responsibility. The development of Sport for All depends on various dimensions, e.g. the different kinds of sport, target groups and aims/motives.
\end{abstract}

Key words: Kinds of sport, target groups, integration and inclusion, dimensions of sport development.

\section{Introduction}

The following article is a statement to the current discussion with integration and inclusion in focus. In all areas of the social and cultural life in families, communities, regions and nations, both the integration of migrants and the inclusion of citizens with impairments or disabilities, for example, are in discussion. Consequently, strategies to put these in practice are essential. No doubt Sport for All is not just a simple slogan, it means that sport should be possible and open for all target groups in the society. But certain persons and target groups still have a very limited chance to participate in (adapted) sport activities.

The author of this article has been working in the field of integration and inclusion in, with and through physical education and sport activities for 40 years. This article is the summary of experiences and results of research projects-both pilot studies and representative studies as well. The reality in the "world of sports" today is not yet developed as integrative and inclusive as possible within the offered

Corresponding author: Peter Kapustin, Ph.D., professor, research field: sport management. programs - being very different in concept and reality from region to region, from country to country, between sport federations and sport providers.

This article is focused on the integration and inclusion of people with impairments and disabilities in the world of sports-from special programs for these target persons and groups to integrative and inclusive sport activities. Sport in this sense is not just a physical activity, but the acting human being is involved mentally, socially, emotionally and physically at the same time. An extra article should be focused on and dedicated to the integration of children, youth and adults from foreign societies and cultures (e.g. migrants and immigrants).

The purpose of this article is to clarify:

- the process of participation, integration and finally inclusion of people (children, youth, families and adults up to the elderly) with impairment and/or handicap/disability in the world of Sport for All;

- the responsibilities for a successful way of integration and inclusion in Sport for All;

- the importance of a barrier-free life in all sections (infrastructure, program and the attitude of all citizens);

- that integration and inclusion cannot be enacted 
- this process must rather be lived in all parts of the society and starts in the "mind and heart" of each person;

- that integration and inclusion in Sport for All development are possible and necessary research areas for scientists, but also study possibilities for students;

- that various, but interdependent dimensions of Sport for All development have to be considered regarding the process of integration and inclusion.

\section{Sport for All}

Sport for All (grassroots sport) means, that for all target persons and groups, for all citizens in villages and cities as well as in all countries there should be possibilities to participate in sport activities. Sport for All is a human right and has important benefits for everyone (e.g. regarding health, fitness, self-confidence, social integration, success experiences). $10 \%$ to $15 \%$ (or even more) of all human beings have to live with a disability/impairment worldwide [1].

\section{Integration and Inclusion}

All persons with disabilities worldwide have the right to be integrated and included in their community and society [2]. Fig. 1 shows the network of institutions in responsibility for inclusion in and through sports in the society.

Integration and Inclusion are hardly to define because they are part of a permanent social process [3] between tolerance, acceptance and participation — embossed by mutual respect, a feeling of togetherness and in responsibility for one another.

Feeling integrated and included in the family or at home, in kindergarten, school, working life and leisure time as well is the main objective of integration and inclusion.

Sport for All offers chances in this process of social integration and inclusion [4]. It is one well-tried way to integrate and to include children, teenagers and adults up to elderly people with disabilities, impairments, emotional disturbances and special needs in the "world of sports" within local communities as well as within the regional, national and international social-cultural life. Social integration is an interactive relationship with active participation in the community life; inclusion is the process to live

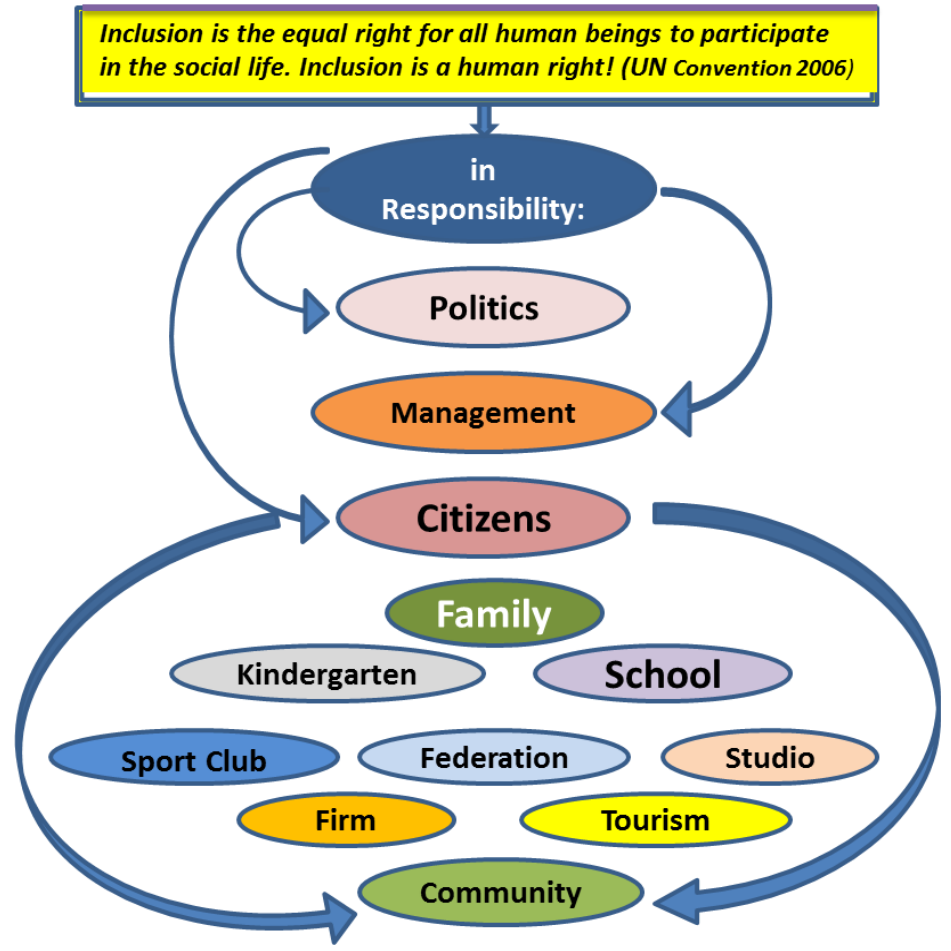

Fig. 1 Inclusion-Network of responsibilities. 
with each other and in responsibility for each other [5].

\section{Steps of Integration/Inclusion in and via Sport}

- Sport (special programs) offered for people with disabilities/impairments (e.g. Paralympics, Deaflympics, sport activities as therapy and as part of a rehabilitation program...)

- Sport for All arranged and organized together with people with disabilities/impairments (e.g. family sport, wheel chair dancing, horseback riding, partial Special Olympics with unified teams, inclusive physical education and sport projects between different schools ...)

- Sport of people with disabilities/impairments in a self-determined way (hiking/wheel chair hiking, nordic walking, swimming, cycling, dancing, skiing, sailing...)

Remark: If there were no possibilities for children, teenagers or adults up to elderly people to participate in sport activities, this could be equated with a segregation out of the world of sports and thus out of the "heart" of communities and the society in the end.

Integration and Inclusion cannot be commanded, but they must rather be lived actively in our families, communities and societies! Maybe the following (German) proverb helps to understand inclusion: "Ich habe dich in mein Herz geschlossen!" ("You are included in my heart!").

\section{5. "The Family that Plays Together Stays Together!"}

This American proverb represents the key idea to state that integration and inclusion (being loved and being partners in the family life) starts within the family. Family sport activities are one chance to strengthen the social cohesion both within and between families.

\section{Politics}

Politicians are responsible for protecting laws, barrier-free sport facilities and infrastructures as well as economic and social conditions in order to create the preconditions for integrative and inclusive sport activities.

\section{Management}

The Management in kindergartens, schools, sport clubs and sport federations, in sport and fitness studios, in tourist areas, communities, firms, homes etc. is responsible for the organization of integration and inclusion regarding the different target groups in Sport for All. It is responsible for communication, networking between relevant organizations (e. g. families, kindergartens, schools, sport clubs, rehabilitation centers) program development, organization, financing and infrastructure.

\section{8. "Mind and Heart"}

But the most important aspect is represented by the attitude in "Mind and Heart" within each one of us - nondisabled and disabled ones. It is normal to be different! Is there anybody without a physical, emotional, mental, intellectual, social disability or impairment?

\section{Dimensions of Sport for All Developments}

Sport development happens in different dimensions (Fig. 2) and is influenced by cultural, religious, social, economic, ecological, educational, political, local and global conditions and trends.

\subsection{Dimension 1: Kinds of Sport—What?}

- World Championships and Olympic Games are only possible, because there are worldwide standardized norms and rules for the global kinds of sport.

- They are applied to all competitions on local, regional, national, continental and worldwide levels.

- Traditional sports, games and dances are characteristics of regional or national cultures with special norms and rules. 


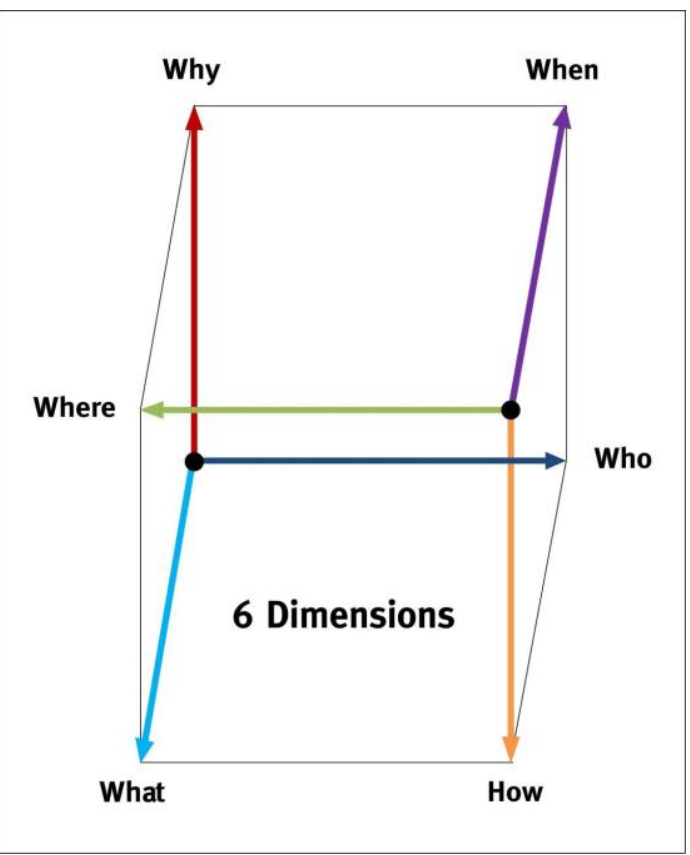

Fig. 26 Dimensions of Sport for All developments.

- Trend sports usually come and go; some of them make their way to established kinds of sport with new developed norms, rules and organization structures.

- The traditional development of sports is orientated according to the various kinds of sport. They have developed parallel and reached a number of far more than 100 meanwhile.

- Kinds of Sport organized in a Soccer/Football Club, Tennis Club, Golf Club, Swimming Club, Skiing Club, Walking Club, Track and Field Club, Gymnastic Club, Sailing Club, Basketball Club, Dancing Club or in a multifunctional Sport Club as well as in private studios or in public communities.

The human being mustn't adapt himself to sport—sport has to be adapted to the human being!

Therefore the first priority in the "World of Sports" should be given to target persons and to target groups, but not to sports with their norms and rules, nor to the commercialization in and with sport.

9.2 Dimension 2: Target groups in Sport for All Who?

With a different point of view in the area of Sport, it can be seen to whom sport should be opened and/or who is already active in sport.

Parameters to define target persons and target groups in Sport for All are for example: (1) age; (2) sex; (3) social relationship; (4) health and fitness; (5) attitude towards life, life experiences; (6) social status and financial possibilities; (7) experiences in and with sport, expectations and motives; (8) cultural background; (9) educational level; (10) way of life/lifestyle and mobility.

Target persons and target groups in Sport for All are for example: (1) Children at different ages (with a rich or poor background, overweight, underweight, handicap, chronical disease anxiety, aggressiveness, shyness, chronically disease, street children...); (2) Youths at different ages, in different social conditions and with various chances; (3) Adults (men and women) up to 50 years of age: About 18-30 years of age; About 30-40 years of age; About 40-50 years of age; (4) Senior citizens with 50 years of age and more: a. Young senior citizens: about 50-65 years of age; b. Senior citizens I: about 65-75 years of age; c. Senior citizens II: about 75plus; (5) Families: a. with infants; b. with school kids; $c$. with children with a

Dimension 1: Kinds of Sport (parallel development)

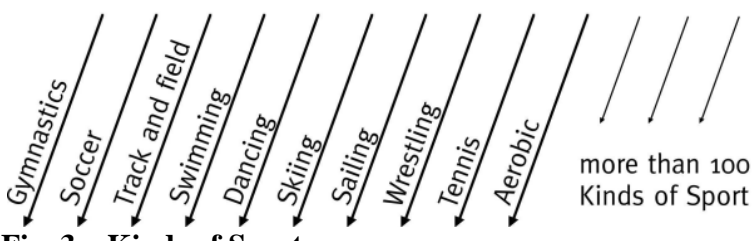

Fig. 3 Kinds of Sport.

\section{Dimension 2: Target groups in Sport for All} and kinds of Sport (network)

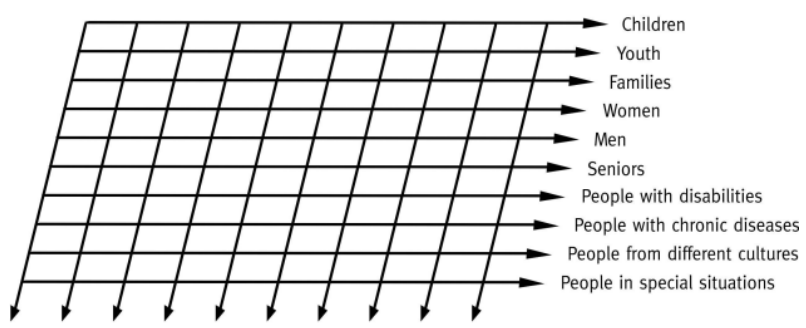

Kinds of Sport

Fig. 4 Target groups. 
handicap/disability; (6) Persons with chronical diseases as for example: Heart attack; Diabetes; Morbus Bechterew; Asthma; Cancer; Mental/emotional illness; (7) Persons with handicap/disability: Physical handicap; Sensory handicap; Mental handicap/mental retardation; (8) People in special life situations: a. From foreign countries and cultures; b. Students; c. Workers; d. Policemen, soldiers; e. Talents in sport, top athletes; $\mathrm{f}$. Tourists in, with and for sports.

Those who are responsible for the Sport for All development in a certain kind of sport on the local, regional or national level in a country are in duty to adapt the conditions, methods, norms and rules of this kind of sport to a suitable variation regarding the selected target group.

Instructors and coaches of a certain target group or target person may choose some suitable variations out of different kinds of sport and try them together in a creative way.

In an Active Community, in an Active City with Active Citizens (TAFISA Triple AC Program!) [6], a network between kinds of sport and certain target groups should be created. A narrow knotted network of Sport for All programs is a chance for (nearly) all target groups/target persons to participate. So the Sport for All network is a kind of social network that can "carry" everybody.

Target groups are organized e.g. in a Kids Club, Youth Club, Family Club, Senior Club, Disabled Club/Paralympics Club, Special Olympics Club, Women Club, Workers Sport Club, Police Sport Club, Army Sport Club, Students Club/University Club or as a Department in a multifunctional Sport Club as well as in private organizations und public communities.

Beside performance and competition in sports, there are more reasons and motives to be active in sports. Sport activities are a part of lifestyle-boosting the personality and being a way to social integration.

Regarding children, youths, families and adults up to the elderly with impairment or handicap, it is necessary to take in focus not only the disabilities of human beings, but it is more important to identify and to strengthen the possibilities of these target persons and groups.

\subsection{Dimension 3: Motives in Sport for All—Why?}

Why does it make sense to be active in sports?

Sport for All is far more than just looking for talents and taking care of their way to become top athletes. Sport for All is an open offer for everybody!

Research programs worldwide certified that Sport for All

- is (sport done in a right way) an important contribution to health at all ages: Sport for fitness, prevention, rehabilitation;

- can be a successful way to social integration and inclusion of people with disabilities, out of foreign countries and cultures, out of different social groups and levels;

\section{Dimension 3: Motives in Sport for All in relation to network out of different Kinds of sport and Target groups}

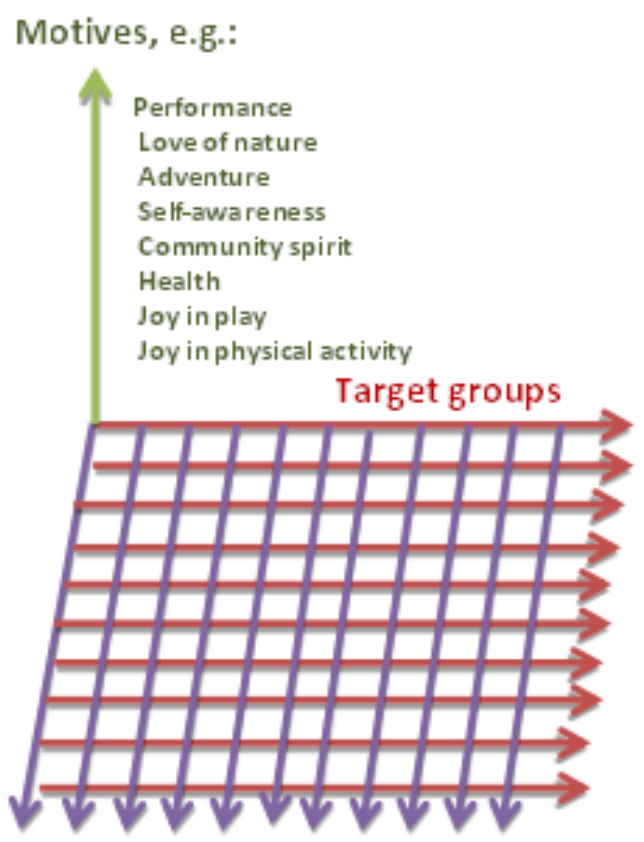

Kinds of sport

Fig. 5 Motives in Sport for All. 
- is indispensable for education;

- strengthens family life;

- is a chance for the well-being at ages of 50plus, 60plus, 70plus. ...

Motives for an active lifestyle in and with sport are for example:

- Joy in physical activity

- Joy in play, games, dances ...creativity

- Health, Fitness, Wellness, Relaxation

- Community spirit

- Self-awareness, Figure-styling, Body-shaping

- Adventure

- Love of nature

- Performance, Competition

Motives orientated programs and activities can be realized in priority for example in a

- Fitness Club/Fitness Studio/Wellness Studio

- Health Club

- Adventure Club

- Nature Club

- Sport Community

- Play Community

For integrative and inclusive Sport for All programs and events, the motives for participation of the target persons and groups are the most important "guidelines" for a successful planning and realization.

9.4

Dimension

4:

Locations/Facilities/Equipment—Where?

Outdoor — nature, stadium, hiking trial, cycle track, sea, pool ... in tourist areas, indoor-gym, fitness center, dancing floor, swimming pool ..., at home, in kindergarten and in schools, in firms...

Facilities for integrative and inclusive sport activities must be barrier-free and the sport equipment should allow easy and riskless success.

\subsection{Dimension: Time and Duration —When?}

In the mornings, afternoons, evenings, daily, only on certain days, weekly, on vacation ...

Depending on the target persons and groups with their possibilities in time management sport programs should have a fixed time-table per week, but also more flexible offers e.g. on weekends or in vacation periods (e.g. children: after kindergarten or school in the afternoons, families: in the late afternoons or at weekends, elderly: in the mornings to early evenings).

9.6 Dimension: Resources and Quality in Sport for All-How?

Quality criteria for Sport for All programs are at first the human resources (educators, coaches, instructors who are responsible for the adapted sport programs), then the organization management, a targeted communication and a social agreeable financing.

It is essential that the group leaders and managers are well trained in the field of integrative and inclusive sport activities regarding different target persons and groups with a variety of motives and abilities.

\section{Proposals for Research Work}

Regarding both the reality and the chances of integration and inclusion of people with impairments, limitations or disabilities, but also of people out of foreign cultures into the local, regional or national Sport for All reality, present chances and best practice programs should be analyzed. However, it is also necessary to identify the target groups' expectations, motives and doubts. Finally, relevant aims and programs should be evaluated with the dimensions of Sport for All development in focus.

\section{Conclusion}

Not the human being has to adapt to norms and rules of sport unconditionally - sport must be adapted to the human being, to certain target persons and groups!

Sport for All is not mainly a popular mass sport, it should also be an individual experience carried by motivation, creativity and responsibility in a network of friends! 
The different kinds of sport, the target groups in sport and the motives for sport activities are important dimensions of the Sport for All development!

Inclusion is sporadically already in process. However, it does not yet represent a general valid reality within our communities', villages' and cities' everyday lives!

\section{References}

[1] Kapustin, P. 2015. "Integration/Inclusion in and with Sport for All-Families, Politics, Management and Citizens in Responsibility." Presented at the International Conference Sport and Physical Activity for Development of the Human Capital, Riga, Latvia.
[2] Commissary of the German Government 2014. What Is Inclusion? Accessed April 22, 2014. http://www.behindertenbeauftragte.de/DE/landkarte/1Wa s/Was_node.html

[3] Wertfein, M. and Lehmann, J. 2015. From Integration to Inclusion. Accessed November 8th, 2013. https://www.familienhandbuch.de/behinderung/behindert e Kinder/

[4] German Olympic Sport Confederation (DOSB). 2014. Diversity, Inclusion, Integration and Interculturalism. Frankfurt, Germany.

[5] City of Munich, Social Services Department. 2013. Intercultural Integration Report-Munich Lives Plurality. Munich, Germany. (in German)

[6] The Association for International Sport for All. 2015. Accessed October 15, 2015. www.tafisa.net. 